\title{
Critical look at physics identity: An operationalized framework for examining race and physics identity
}

\author{
Simone Hyater-Adams, ${ }^{1}$ Claudia Fracchiolla, ${ }^{2}$ Noah Finkelstein, ${ }^{3}$ and Kathleen Hinko ${ }^{4}$ \\ ${ }^{1}$ ATLAS Institute, University of Colorado Boulder, Boulder, Colorado 80309, USA \\ ${ }^{2}$ University College Dublin, School of education, Belfield, Dublin 4, Ireland \\ ${ }^{3}$ Physics Department, University of Colorado Boulder, Boulder, Colorado 80309, USA \\ ${ }^{4}$ Department of Physics and Astronomy, Lyman Briggs College, Michigan State University, \\ East Lansing, Michigan 48824, USA
}

(Received 7 June 2017; published 1 June 2018)

\begin{abstract}
Studies on physics identity are appearing more frequently and often responding to increased awareness of the underrepresentation of students of color in physics. In our broader research, we focus our efforts on understanding how racial identity and physics identity are negotiated throughout the experiences of Black physicists. In this paper, we present a Critical Physics Identity framework that can be used to examine racialized physics identity and demonstrate the utility of this framework by analyzing interviews with four physicists. Our framework draws from prior constructs of physics identity and racialized identity and provides operational definitions of six interacting dimensions. In this paper, we present the operationalized constructs, demonstrate how we use these constructs to code narrative data, as well as outline three methods of analysis that may be applied to study systems and structures and their influences on the experiences of Black students.
\end{abstract}

DOI: 10.1103/PhysRevPhysEducRes.14.010132

\section{INTRODUCTION}

Black physicists are significantly underrepresented in physics, and the percentage of Black students obtaining physics bachelor's degrees is declining [1,2]. Because of this, the physics field offers a useful space for analysis to further understand how to shift the culture and practices in science, technology, engineering, and mathematics (STEM) that have historically excluded people of color. Simultaneously, there is a breadth of research that examines the ways that race impacts the experiences of students of color in STEM. These studies show how the culture of academia broadly, and even more so STEM disciplines, creates an unwelcoming and unhealthy place for people of color. In the physics education research field, researchers have been using physics identity to understand issues of recruitment and retention. However, the way physics identity frameworks are commonly used does not explicitly critique the culture of the field.

In this paper, we aim to add to theoretical discussions about identity in physics to address the need for more tools to understand physics identity and its implications for equity in physics. We contribute to this body of work by offering a more holistic framing for physics identity that explicitly examines

Published by the American Physical Society under the terms of the Creative Commons Attribution 4.0 International license. Further distribution of this work must maintain attribution to the author(s) and the published article's title, journal citation, and DOI. broader structures and systems at work within the culture of physics. For this holistic framing, we use a commonly taken up physics identity framework [3] and put it in conversation with a racialized identity resources framework [4] from literature on math education. We use these frameworks together with a goal of considering identity at an internal, interpersonal, and institutional level, with special attention to the intersections of racial and physics identities.

This paper describes the development of a new tool and methodological approach for examining physics identity. In the Sec. II, we situate our work within broader identity studies. We then provide a detailed overview of our process for operationalizing the framework, present the definitions of our operationalized constructs within this framework, and share our analysis process. In our discussion, we demonstrate what types of findings this framework can provide, its limitations, and our future plans for its use. We intentionally frame this and future work as directed to physics education researchers and the broader physics community, in order to provide and demonstrate a tool and associated methods for critically examining the culture and norms of the physics discipline.

\section{BACKGROUND}

\section{A. Identity, race, and gender in STEM}

There is much research focused on understanding and addressing racialized and gendered experiences in STEM [5-9]. Within this literature, studies investigate the experiences of people of color and women in the K-12 [10,11], 
undergraduate [12-14], graduate [14-16], and professional $[17,18]$ phases of their STEM careers in order to understand the reasons for their underrepresentation. The findings from these studies typically include insights into the STEM experiences of people of color and women, as well as areas within STEM culture and institutions that could be changed in order to better support these groups. Amongst these are things like improving mentorship experiences $[18,19]$, financial support $[19,20]$, and combating racism and sexism in departments and classrooms [21-27]. There are also studies that focus on understanding the ways that science impacts the "sense of self" of women and people of color. Through the study of constructs like belonging [27-30], self-efficacy and agency [30-35], and identity [35-40], the broader STEM education community is pushing to understand the issues that continue to exclude women and people of color. In the related literature particular to the physics experience, there are several studies that look into these themes specifically for women of color in physics [34,41-43]. These studies have focused heavily on collecting, documenting, and analyzing the experiences of women at various stages of their careers.

Amongst existing studies on identity and the experiences of physicists of color, many focus on the intersection of race and gender, and highlight themes of systemic and institutional norms and practices that impact physicists at this intersection. Rosa and Mensah [41] document and analyze the pathways of six Black women physicists from survey and interview data. Their work provides useful recommendations for the field in its push to recruit and retain more Black women physicists that include similar themes mentioned above, while highlighting the importance of after school and outreach programming, self-efficacy in choosing a physics major, and financial support. An ethnographic study conducted by Mia Ong followed 10 women of color through their undergraduate physics careers and into their graduate and professional positions [42]. This longitudinal study on identity uses body theory to investigate the ways these women enacted practices of fragmentation (i.e., gendered and racial passing) or multiplicity (i.e., stereotype manipulation and performing superiority) as they attempted to negotiate their intersecting identities. Her findings highlight the struggle for the women of color in the study to be "ordinary" in the physics field and overview implications, similar to those outlined above, for changes at the structural level that can better support women of color in physics. Ko et al. [43] builds from this work in a study of narratives from women of color in physics and astronomy and found broad themes of career-life balance and volunteer work. Kachchaf et al. continues this work in a study that highlights the agency of women of color in physics and astronomy and outlines the strategies these women use to succeed. It also provides recommendations to departments and organizations on how to better support women of color [34].

Our work looks to add to the discussions in this literature aimed at understanding the experiences of people of color and women in physics. In order to do so, we frame physics identity in a manner that allows researchers to critique the culture of physics, or more specifically the institutional factors that impact the trajectories of physicists. In a literature review by Ong et al. on research about women of color in STEM [14], there is a call to develop theoretical and conceptual frameworks to address the issues of these and other marginalized groups in STEM. Here we take up this call by developing a framework and methodology that can be applied to narrative interviews about the experiences of physicists of color. In Sec. IIB, we outline the frameworks we draw from in order to do so.

\section{B. Identity frameworks}

We think of identity as one's sense of self that is always being shaped and impacted by one's environment. This perspective aligns with Vygotskian ideas of how one molds themselves constantly in relation to the world around them [44]. In the physics education research field, we take up the construct of identity to understand student trajectories into the field as well as to understand the reasons why some students decide not to enter or stay in the field [45-47]. In this work, we look to complicate the ways physics education researchers frame and measure how people identify with the physics discipline. We take a critical race perspective, which is based on the premise that racism is normalized and engrained within our systems, institutions, and societal norms [48]. By presenting a methodology that takes into consideration the impact of one's environment, we pay special attention to how one's racial background shifts the impact of the environment on their sense of self. In this paper we focus specifically on the development and validation of our framework and how it elicits important differences between the stories of two white physicists and two Black physicists. In future work, we plan to use this framework to analyze interviews of a larger sample of Black physicists.

Early efforts at developing a science identity framework can be seen in Carlone and Johnson's [39] longitudinal study that proposed and tested constructs for science identity. This work followed fifteen women of color in STEM fields including biology, chemistry, medical sciences, and anthropology through undergraduate and graduate studies. Their data included interviews and long answer email surveys. The model for science identity that was tested in this work included three components: performance (of required tasks), competence (in required content), and recognition (as a scientist). The sample used by Carlone and Johnson included women from many racial backgrounds in mostly natural science fields and included several Black women and no physicists. The results of their study showed that the most impactful component of this model was recognition. They found that recognition could be either an internal or external source, and affect the subject positively or negatively. We draw from this work 
and in Sec. III D, we will discuss how these findings align with our operationalization process.

Hazari et al. [3] used Carlone and Johnson's framework on science identity to create a discipline-specific framework for physics identity that includes four constructs. This framework has been taken up in many studies in the physics education literature $[40,45-47]$. The physics identity constructs include recognition from others as a good physics student, interest in physics content, competence, defined as the ability to understand physics content; and performance, defined as the ability to perform required tasks. Hazari et al. used data from a survey of physics identity administered across institutions nationwide in introductory college English classes and analyzed these data quantitatively to find correlations between the identity constructs. Results from this work show relationships between competence and performance suggesting that those constructs show up similarly in data, as well as strong correlations of interest and recognition with persistence in the field. Although Hazari et al.'s work pulls from a framework for women of color, race is not examined in the analysis, although it is controlled for, and it is not a central focus of the constructs.

In order to centralize issues of race in this work, we draw from the critical theory in Black feminist literature that stresses the importance of being critical of societal structures of oppression. P. Hill Collins outlines the facets of Black Feminist Thought [49], a critical social theory rooted in the experience and knowledge of Black women, three of which we explicitly draw from in this work. The first facet is the importance of linking experiences with ideas and knowledge, which is reflected in our data collections methods. The second is the importance of considering the heterogeneous collective, which is reflected in our future goals to use this framework to categorize experiences from a heterogeneous group of Black physicists. The third is the importance of taking up work by Black women scholars, which is reflected in our decision to foreground a racialized identity resources framework [4] created by a Black woman scholar in developing our concept of a Critical Physics Identity and by the lead author of this paper. We take these approaches called for by Hill Collins [49] to address the reality that students' racial identities, which precede their science and physics identities, impact the ways that they do or do not take up resources, which may or may not be available, while they pursue a physics career.

Complementing the physics identity framework above, we draw from Nasir [4], who provides a framework to think about racial identity, which she developed in the context of math education. This model examines what she coins as racialized identity through the availability of resources in different learning environments. Nasir defines three broad resource categories in her work: ideational, material, and relational resources. Ideational resources are defined as ideas about oneself and one's relationship to and place in a practice and the world, as well as ideas about what is valued and what is good. Material resources are the ways physical environment, its organization and the artifacts in it support one's sense of connection to a practice. Relational resources are defined as the way in which positive relationships with others in the context can increase one's connection to a practice. In her work, these categories of resources were used to analyze observational data about experiences of Black high school students in different learning environments. We take these resource categories and apply them to data outside of a set environment in order to analyze social structures and institutions that impact one's life experiences. For example, Nasir defines material resources as objects in a local learning environment (i.e., a chalkboard, basketball, or computer), we expand this definition to include larger physical structures (i.e., a physics class, an organization, or school).

We postulate that when used together, these identity frameworks can help us show how physics identity differs for physicists across racial or ethnic backgrounds and help us gain a more holistic understanding of the facets of identity that are important in the process of developing a physics identity. The broad resource categories that Nasir defines for racialized identity complement the more narrowly defined constructs that Hazari et al. define for physics identity. In this paper, we combine these frameworks to analyze the stories of physicists from different backgrounds (Fig. 1). Drawing from the ideas of other Black feminist scholars who stress the importance of resisting systems of oppression, including b. hooks [50], we use our combined identity framework to create a tool that allows us to examine broader societal structures in our work. In future work, this analysis will elucidate common facets of physics identity for Black physicists and the roles of institutional structures.

From our preliminary studies [51-52], we find potential for this framework to identify important differences in experiences between Black and white physicists. The first pilot study used methods of narrative inquiry along with Nasir's racialized identity resources in order to show the differences in the pathways of four physics graduate

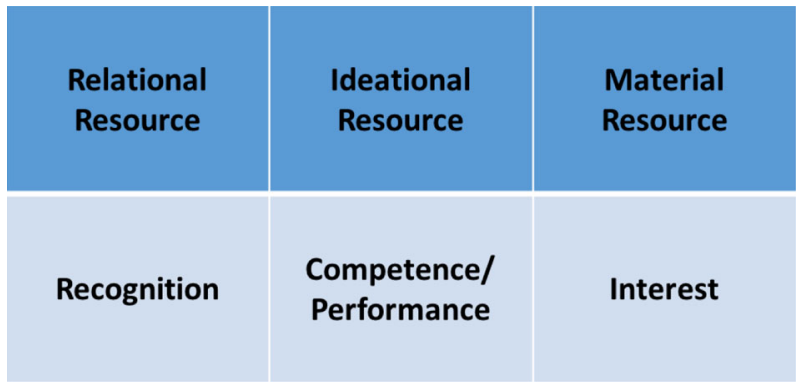

FIG. 1. The constructs drawn from to develop the Critical Physics Identity framework. The bottom gray row shows constructs drawn from the physics identity framework [3]. The top blue row shows the constructs drawn from the racialized identity resources framework [4]. 
students [51]. From this work, we were able to establish two useful findings: Nasir's framework could be used successfully in a coding process of narrative data, and these codes revealed important information about the ways different types of students experience the systems within physics. The second study was our initial work that developing operationalized codes for two of the identity constructs [52]. Specifically, we focused on Hazari et al.'s [3] recognition and Nasir's [4] relational resource constructs. This preliminary work's findings showed us that the two frameworks were linked theoretically and empirically, and that they can pick up important differences between interviews of physicists from different demographic backgrounds.

In this paper, we look to answer the following research questions: Can we combine the separate constructs for physics identity and racialized identity to provide a more holistic framework for physics identity that considers racialized experiences in the field? How can we operationalize (create a useful coding scheme to specify elements of) these constructs? Can we use this newly realized framework to demonstrate how race impacts the ways that people identify with the physics discipline by picking up differences in the experiences of Black and white physicists? In this work we examine the last two questions in order to answer the first. We present an operationalized Critical Physics Identity framework that can be used to examine the intersection of race and physics identity. We demonstrate the methods we use to analyze four interviews using this framework and give examples of the ways that this analysis can evoke the systemic and structural barriers that Black students face when pursuing physics. We describe our process of operationalizing and coding constructs from existing racialized identity and physics identity models, demonstrate how to use our new framework, and give examples of the types of findings it can provide. Finally, we present preliminary connections between our operationalized constructs and present a preliminary model for these connections.

\section{METHODS}

\section{A. Narrative inquiry}

To further align with our Black feminist lens as discussed above, we place experiential knowledge in the forefront of our data collection by conducting interviews crafted to gather personal stories, or narratives, of physicists to identify important aspects of their experiences. Narrative inquiry is a broadly used methodology for qualitative research, which is premised on the idea that people understand and give meaning to their lives through story [53]. In this work, we operationalize the identity constructs for use in qualitative analysis of narratives. Through this process of redefining the constructs, we are able to see connections between the facets of physics identity and the types of resources that may or may not be available along one's path to the field that influenced that identity. Once coded, we can conduct analyses that highlight the complex structures at work when developing a physics identity. This approach ensures that the theoretically developed framework can provide implications for changes in practice, in order to inform future efforts and understand current practices.

We have designed a semistructured interview protocol in order to elicit stories from subjects about their experiences while pursuing a career in physics [54]. Some questions include "How did you end up in physics?", "Can you describe a 'typical' physicist?", and "What difficulties have you faced pursuing the field?" The interview protocol was developed with the narrative goal in mind. The interviews were administered by the first and second authors, and varied from approximately forty minutes to one-hour long. Each interviewee was asked to complete a demographic survey after the interview, so that the demographic questions we ask do not impact the participant's answers to the interview questions. After the interview process, the audio was transcribed by a third-party transcription service. Interviews were coded in Nvivo through an iterative process that cycled through individual coding, where one member coded an interview alone, and then group coding where the individually coded interviews were discussed and agreed upon amongst the full research group. We discuss this process in more detail in the Sec. III. D.

\section{B. Subjects}

In the process of operationalizing our framework, we intentionally used interviews with Black and white physicists because we are interested in how the constructs can differentiate between Black physicists and physicists from the most highly represented demographic in the field. We define a "physicist" as being someone close to or already having received a bachelor's degree in physics. Because we focus on physicists already in their careers, we work with the assumption that all of our participants have an existing physics identity. Our overall participant pool includes upper level undergraduates (juniors and seniors), graduate students, postdocs, and professional physicists with a bachelor's degree and above. To date, 36 interviews have been conducted, yet we select four participants from this larger sample for this work. We recruit most of our white identifying participants from the volunteer base of an informal science program out of the University of Colorado Boulder (CU) called Partnerships for Informal Science Education in the Community (PISEC) [55]. PISEC is an afterschool program that has a volunteer base of physicists (undergraduates, graduates, and postdocs) from the CU physics department and JILA Physics Frontier Center. Because this volunteer base reflects the demographics of CU Physics department (mostly white and male), we additionally used Black physicist social networks 
via Facebook groups, national organizations, and national conferences in order to recruit Black physicist participants. In this paper, we focus specifically on four interviews from our sample that are used to develop this framework. We intentionally included men and women in order to capture differences in experiences due to gender as well, although we focus our examination on differences across racial demographics. The sample consisted of Cara, a Black woman who already has her Ph.D. and is working professionally, Jeff, a white man who recently received his bachelor's degree and is on his way to graduate school, Cindy, a white woman who is in the middle of her graduate career, and Owen, a Black man who is also in the middle of his graduate career. All names are pseudonyms and all potentially identifiable people have reviewed the use of their data in this paper.

\section{Research team}

It is important to acknowledge that there is bias in any study that involves human interpretation. We consider the identities of the research team as a measure of validity for our analysis process. The experiences that each member has had in their physics pathway gives insight into the types of systemic patterns that we look to expose with this analysis. Our team of raters includes physicists who are at the graduate student, postdoctoral, and professor level. Our coding team includes a white woman, a Latina woman, and an African American woman. We believe the identities within the team strengthen the interpretations agreed upon by the group. There is a history of the stories of people of color being altered when told from the lens of white counterparts [56]. So, we view the identities of our research group, which includes a woman from a Latina background and a Black woman, to be particularly useful in shaping the narrative. The lived experiences that the members of the research team provide a familiarity that is useful in the interpretation of each narrative. Using a peer review and consensus-based approach to the coding and interpretation of the interviews (see Sec. IIID) we provide a validation of the methods. In addition to the lens of the research team, our process includes the input of interviewees after analysis.

\section{Operationalizing the critical physics identity constructs}

Our process of operationalizing the Critical Physics Identity constructs was iterative. The procedure began with the original definitions of the racialized identity and physics identity constructs from the two separate models (Hazari et al. [3] and Nasir [4]). In this process, we used a combination of emergent themes from the data and the original definitions of the constructs to create subcodes for analyzing interview data. Notably, subcodes we found in our process align with findings from Carlone and Johnson's findings for their recognition construct, which we see as a validity check for our process. Their recognition construct was specified with internal or external and positive or negative categories (see Tables 2-4 in Ref. [39]). As described below, we find similar themes from our operationalization process, and assign similar categories to the constructs in our framework. We used an iterative coding method where two people coded the same data, and validated codes in a group of three that included one person who did not code individually. Once there was consensus among the three about what codes reflected the narrative best, the definitions were refined to more clearly describe the category. This process repeated for each construct using Cara's interview, and again for Owen, Cindy, and Jeff's interviews. Once the codes were agreed upon amongst the research group, they were validated by a group of physics education researchers not on the project, through a group coding activity. Based on the feedback from this group we defined clearer boundaries between the constructs. Finally, all codes were agreed upon by our three-person research group before being updated in our codebook.

As needed, we adapted original definitions of the three racialized identity resource categories to be physics specific. For example, a relational resource by Nasir's definition increases one's connection to a practice, but in our work, this practice is physics. Similarly, we changed the other resource definitions to be physics specific and attempted to code the transcript from Cara. During this process, the need for subcodes emerged in order to accurately categorize details of her narrative. When it became clear that there were many connections between the constructs, we looked for theoretical links to find a starting point. We began operationalizing the recognition and relational resource constructs because of the strong theoretical link between them. The original definition of recognition from Hazari et al. is "recognition from others as a good physics student." As discussed below and in preliminary studies [52], we see a direct link to Nasir's relational resource construct which she defines as "the way in which positive relationships with others in the context can increase one's connection to a practice," because it can be implied that recognition can come from a relationship. Results from the process of operationalizing recognition and relational resources revealed links to ideational resources. Because of this, we chose ideational resources as the next construct to operationalize. Through the process of coding for ideational resources, we were able to find connections to material resources. It became apparent that in many of the places that one of the other constructs were coded, there was a material resource that provided the context or setting in which the other constructs appeared. The interest and competence or performance constructs was the last to be operationalized and refined. Because they were already physics specific, the process of operationalizing centered on how these showed up in data in relation to 
the other codes. We present the definitions of our operationalized codes in Sec. IV.

\section{DEVELOPING THE CRITICAL PHYSICS IDENTITY CONSTRUCTS}

Through the process of coding the four interviews, of Cara, Owen, Cindy, and Jeff, we were able to define and create subcodes for our Critical Physics Identity constructs. The operationalized codes and their subcodes not only provide a systematic method to examine each participant's physics journey, but they also provide us with the language to talk about the structural and institutionalized impacts of the current physics culture on students trying to pursue the field. The process of operationalizing the constructs was empirical and the links between the racialized identity resource constructs and the physics identity constructs emerged naturally as we coded the data. The connections we found between the physics and racialized identity constructs provide evidence of the overlapping nature of the original frameworks. In Sec. V, we present our Critical Physics Identity constructs: three resources and three physics identity constructs. The following sections outline the individual definitions and subcodes of each construct and include a complete table of each construct and code definition at the end.

\section{RACIALIZED IDENTITY RESOURCES}

\section{A. Relational resources}

For the context of this study, we define relational resources as the way in which an aspect of a relationship with others in the context can impact one's connection to physics. We break this construct into the subcodes of positive and negative as well, still being defined as encouraging or discouraging participation in physics. We do not use the internal or external codes here, as we define all relational resources to be external. The internal impacts that relationships have are captured in the ideational resource category defined in Sec. VB. We highlight that this definition focuses on aspects of a relationship, rather than the relationship itself in order to highlight the multiple ways that one relationship can function as a resource. For example, there can be many relational resources that come from a relationship with one's parents. Jeff talks about his parents, he mentions how he knew he was going to do something in science because both of his parents were scientists: "I knew I was going to do science and then just sort of signed the papers and was like I guess I'm a physics major now, you know? Like it wasn't, it was just something that I was always going to do because my parents were both scientists." Later on he talks about how his parents' upbringing impacted his views of the world and of science: "I'm a middle class white dude, but knowing my parents' experiences has informed the way that like I go about, you know, pursuing my education and thinking about the world and things like that." These would be coded as two separate positive relational resources even though they both come from the relationship he has with his parents. Cara talks about her high school physics teacher and how his class got her interested in the subject: "I took it and I actually loved it. My teacher was great." However, later on in her story mentions that he told her physics was only for boys who wanted to be engineers: "I told him that I was thinking about majoring in physics in college, and he told me physics was for guys who were going to be engineers so I should think about something else." We code the first part of her story as a positive relational resource and the last as a negative relational resource, even though both come from the same relationship. With these distinctions, we are able to elucidate these details in order to gain a comprehensive picture of the participants' stories. We outline these definitions in Table I.

TABLE I. Details of our relational resource construct code definitions. This includes the definition of the main construct, as well as the definitions of each subcode and example from the interviews of Cara, Jeff, Cindy, or Owen.

\begin{tabular}{|c|c|c|}
\hline Code & Subcodes & Example \\
\hline \multirow{3}{*}{$\begin{array}{l}\text { Relational resource: The way } \\
\text { in which an aspect of a } \\
\text { relationship with others in the } \\
\text { context can impact one's } \\
\text { connection to physics }\end{array}$} & $\begin{array}{l}\text { Positive: When an interviewee mentions a } \\
\text { unique aspect of a relationship that } \\
\text { encouraged them to participate }\end{array}$ & $\begin{array}{l}\text { "I didn't care for the chemistry professors } \\
\text { whereas the physics professors were } \\
\text { awesome." }\end{array}$ \\
\hline & $\begin{array}{l}\text { Negative: When an interviewee mentions a } \\
\text { unique aspect of a relationship that } \\
\text { discouraged them to participate }\end{array}$ & $\begin{array}{l}\text { "When I was thinking about going to college I } \\
\text { talked to my high school physics teacher and } \\
\text { I told him that I was thinking about majoring } \\
\text { in physics in college, and he told me physics } \\
\text { was for guys who were going to be engineers } \\
\text { so I should think about something else." }\end{array}$ \\
\hline & $\begin{array}{l}\text { Neither: When an interviewee mentions a } \\
\text { unique aspect of a relationship that was } \\
\text { impactful, but they do not specify whether it } \\
\text { encouraged or discouraged their } \\
\text { participation. }\end{array}$ & $\begin{array}{l}\text { "I've gone to teach in a classroom and I've had } \\
\text { people shocked that I was a professor, so I } \\
\text { can't say what the shock was about" }\end{array}$ \\
\hline
\end{tabular}




\section{B. Ideational resources}

Nasir defines ideational resources as ideas about oneself and one's relationship to and place in a practice and the world, as well as ideas about what is valued and what is good. This description for ideational resources is very broad and includes multiple definitions. We were able to create subcodes for the construct by breaking apart the original definition and making them physics specific. The ideational resource subcodes include positioning in physics, what is valued and good in physics, personal characteristics, and perceptions of physicists. We define positioning in physics as ideas about one's place in physics and how one negotiates their position within the physics community. What is valued and good in physics is defined as ideas about what physicists care about and value within the community. The personal characteristic subcode is defined as ideas about who you are as a person including your struggles, strengths, and weaknesses, and personality traits. We define the perceptions of physicists code as cultural perceptions about who or what physicists are from those within and outside of the field. Each code can be either internal or external, similar to recognition, where we define internal as what the interviewee thinks, and external as what others think. We distinguish this in data through the language used by the participant; when they are discussing what they believe we code as internal, but when they are discussing what they say someone other than them believes we code it as external. We intentionally distinguish the what is valued and good in physics as comments from the interviewee or other people within the field of physics so that it is not confused with the external perceptions of physicists code. An example of something we coded as an external perception of physicist can be seen when Owen comments on his family's view of him: "they see me as the brain child I guess." Alternatively, when he discusses the ways physicists identify other physicists we code an external what is valued and good in physics: "amongst physicists I think it's a little tricky because you've got, you know, you've got some physicists that don't see astrophysics or astronomy as physics, or even in PER, like well is PER really physics?" These definitions were refined to their current definitions through a process of coding the four interviews and clarifying the differences in the categories. We cumulate them under a new broad definition for ideational resources: aspects of an idea that impact one's connection to physics. See Table II for the ideational code and subcode definitions, as well as examples from the data.

\section{Material resources}

Nasir defines material resources as the ways in which physical environment, its organization, and the artifacts in it

TABLE II. Details of our ideational resource construct code definitions. This includes the definition of the main construct, as well as the definitions of each subcode and example from the interviews of Cara, Jeff, Cindy, or Owen.

\begin{tabular}{|c|c|c|c|}
\hline Code & Subcodes & & Examples \\
\hline \multirow{6}{*}{$\begin{array}{l}\text { Ideational } \\
\text { resource: } \\
\text { Aspects of } \\
\text { an Idea that } \\
\text { impact one's } \\
\text { connection to } \\
\text { physics }\end{array}$} & $\begin{array}{l}\text { Positioning in physics: Ideas about } \\
\text { one's place } \mathrm{n} \text { physics/how one } \\
\text { negotiates their position within } \\
\text { the physics community }\end{array}$ & $\begin{array}{l}\text { External: Others' ideas } \\
\text { (What others think) }\end{array}$ & $\begin{array}{l}\text { "I've never had to struggle with not seeing } \\
\text { myself as Ale to do It or not being perceived } \\
\text { as a person who could do it. } \\
\text { “...there's a large group of people who would } \\
\text { not call me a physicist." }\end{array}$ \\
\hline & \multirow[t]{2}{*}{$\begin{array}{l}\text { What's valued/good in physics: } \\
\text { Ideas about what physicists care } \\
\text { about and value within the } \\
\text { community }\end{array}$} & $\begin{array}{l}\text { Internal: Your ideas } \\
\text { (what you think) }\end{array}$ & $\begin{array}{l}\text { "I always thought I was bad at math, and I } \\
\text { always like thought that I wasn't going to do } \\
\text { anything to do with math because I was bad at } \\
\text { math" }\end{array}$ \\
\hline & & $\begin{array}{l}\text { External: Others' Ideas } \\
\text { (What others think) }\end{array}$ & $\begin{array}{l}\text { "There are like these strands that are kind of } \\
\text { respected and common for physics education } \\
\text { researchers to go into..." }\end{array}$ \\
\hline & $\begin{array}{l}\text { Personal characteristics: Ideas about } \\
\text { who you are as a person (your } \\
\text { struggles strengths/weakness, } \\
\text { personality traits, etc. }\end{array}$ & $\begin{array}{l}\text { Internal: Your ideas } \\
\quad \text { (what you think) } \\
\text { External: Others' Ideas } \\
\quad \text { (What others think) }\end{array}$ & $\begin{array}{l}\text { "I think I come in with a different perspective } \\
\text { because my motivations are different... I } \\
\text { think the questions that I ask are different" } \\
\text { "One of my major professors at [my institution] } \\
\text { said this about me, he was like you are the } \\
\text { kind of person who will fix situations to make } \\
\text { yourself happy or you'll leave." }\end{array}$ \\
\hline & \multirow{2}{*}{$\begin{array}{l}\text { Perceptions of physicists: Cultural } \\
\text { perceptions about who/what } \\
\text { physicists are from those within } \\
\text { and outside of the field }\end{array}$} & $\begin{array}{l}\text { Internal: Your ideas } \\
\text { (what you think) }\end{array}$ & $\begin{array}{l}\text { "...physics is so dominated by white males is } \\
\text { just not sustainable. I mean, It's not optimal. } \\
\text { It's not optimal..." }\end{array}$ \\
\hline & & $\begin{array}{l}\text { External: Others' ideas } \\
\text { (What others think) }\end{array}$ & $\begin{array}{l}\text { "there's a perception of a typical physicist and } \\
\text { like let's be real here, its usually a white } \\
\text { dude." }\end{array}$ \\
\hline
\end{tabular}


TABLE III. Details of our material resource construct code definitions. This includes the definition of the main construct, as well as the definitions of each subcode and example from the interviews of Cara, Jeff, Cindy, or Owen.

\begin{tabular}{|c|c|c|}
\hline Code & Subcode & Example \\
\hline \multirow{3}{*}{$\begin{array}{l}\text { Material resources: Material } \\
\text { things that can provide access } \\
\text { to other identity constructs, } \\
\text { (i.e. programs, communities, } \\
\text { organizations, funding) }\end{array}$} & Positive: Provides access to & $\begin{array}{l}\text { "I went to a women's college which was great because } \\
\text { there were like ten other women there who were also } \\
\text { physics majors." }\end{array}$ \\
\hline & Negative: Prevents access field & $\begin{array}{l}\text { "I started a PhD in physics in } 2006, \mathrm{I} \text { think? and I quit, } \\
\text { and that was a big thing for me." }\end{array}$ \\
\hline & $\begin{array}{l}\text { Neither: But it is not clear whether it } \\
\text { provided or prevented access. }\end{array}$ & $\begin{array}{l}\text { "I was a presidential scholar so I had to do so many hours } \\
\text { of service..." }\end{array}$ \\
\hline
\end{tabular}

support one's sense of connection to a practice. We redefined material resources as material things that can provide access to other identity constructs (i.e., programs, communities, organizations, funding). We also create similar positive or negative subcodes for material resources, which we define as providing access or preventing access to the other identity constructs. Common things coded as material resources were classes, class assignments, seminars, and research or outreach programs. An example of this is when Cindy talks about her first-year graduate classes: "Like I took some physics-I took like the quantum physics core classes and I was like oh my god, like it was really hard." We specifically define groups of people or communities of people as a material resources rather than a relational resource in order to account for social groups relating to physics. We also distinguish one directional relationships embedded in systems as material resource. An example of this type of material resource could be an academic advisor. Because every student is given an academic advisor through their institution, the nature of the relationship can commonly be one sided, where the student only interacts with them to sign off on classes. The ways that material resources show up in the data is through the context of the stories told. An example would be in the narrative of Owen where he discusses a seminar at his undergraduate university that brought in a speaker who told him and his classmates that they were physicists regardless of what messages others send them: "he was telling us once you get your bachelor's you are a physicist, like that doesn't make you any less of a physicist than anybody else whether they went to MIT, or Yale, or Georgia Tech, like you're still a physicist." This seminar is coded as a positive material resource that provided the access to a positive relational resource that impacted him through a positive ideational resource about who "counts" as a physicist. See Table III for definitions and examples of the material resource codes and subcodes.

\section{PHYSICS IDENTITY CONSTRUCTS}

\section{A. Recognition}

We define recognition similarly to Hazari et al. as being recognized as a physicist or physics person. We add "as a physics person" as a way to account for events in stories prior to when an interviewee became a physicist. We break this construct into four subcodes: positive and negative, which we define as encouraging or discouraging participation in physics, and internal and external, which we define as recognition from oneself or recognition from others, respectively. We note that the definition of positive and negative is carefully designed to pick up events in a narrative that lead to participation in physics, and not to make any statements about whether the event had a positive or negative effect on the participant. For example, Cara told a story about an advisor who would not sign off for them to take calculus-based physics due to his belief that she could not "handle it." This is coded as negative external recognition. However, later in her story she talks about forging his signature in order to take it anyway - this we code as positive internal recognition. A full overview of the recognition codes is shown in Table IV.

\section{B. Interest}

Our definition for interest is interest in the physics field and is broken into subcodes of content and noncontent. We define the content subcode as interest in physics content, such as physics ideas, classes, and research. Noncontent is interest in physics for reasons other than physics content. These definitions can also be coded as positive or negative, similar to relational resources, as encouraging and discouraging participation in the physics, respectively. We create these subcodes in order to account for the ways that disinterest in other subjects can lead to interest in physics. If a participant talks about how hating English classes and writing encouraged them to pursue physics, this would be coded as positive content interest. The noncontent code was developed from an emergent theme from the data, where interviewees would discuss reasons other than their interest in the physics they were doing that kept them interested in the field. Cindy discusses an interest in increasing representation of women in physics: "I feel strongly about getting more girls to do physics..." Owen expresses the cultivation of more Black physicists as a goal of his career: "I want to transform it so that other Black physicists that come out of here....And I may not be the one that does high energy physics but I would love to nurture and cultivate young physicists that will be doing that". See Table V for the interest code definitions and examples. 
TABLE IV. Details of our recognition construct code definitions. This includes the definition of the main construct, as well as the definitions of each subcode and example from the interviews of Cara, Jeff, Cindy, or Owen.

\begin{tabular}{|c|c|c|c|}
\hline \multirow[t]{3}{*}{ Code } & \multicolumn{2}{|c|}{ Subcodes } & \multirow{2}{*}{$\begin{array}{l}\text { Example } \\
\text { "Do I identify as a physicist? Uh, yes and no. } \\
\text { Yes because I do have my degree, my } \\
\text { bachelor's in It..." }\end{array}$} \\
\hline & $\begin{array}{l}\text { Internal: When an } \\
\text { Interviewee mentions } \\
\text { getting recognition from }\end{array}$ & $\begin{array}{l}\text { Positive: Recognition that } \\
\text { encourages participation } \\
\text { in physics. }\end{array}$ & \\
\hline & $\begin{array}{l}\text { themself as being a } \\
\text { physicist }\end{array}$ & $\begin{array}{l}\text { Negative: Recognition that } \\
\text { discourages participation } \\
\text { in physics }\end{array}$ & $\begin{array}{l}\text { "I do feel a little bit like an imposter at } \\
\text { conferences" }\end{array}$ \\
\hline \multirow{4}{*}{$\begin{array}{l}\text { Recognition: Being } \\
\text { recognized (or not) } \\
\text { as a physicist or } \\
\text { physicspeison }\end{array}$} & \multirow{4}{*}{$\begin{array}{l}\text { External: When an } \\
\text { interviewee mentions } \\
\text { getting recognition from } \\
\text { others as physicist }\end{array}$} & $\begin{array}{l}\text { Neither: Recognition that is } \\
\text { not clear whether it } \\
\text { encouraged or } \\
\text { discouraged their } \\
\text { participation. }\end{array}$ & $\begin{array}{l}\text { "Like there's no way that I would be strong } \\
\text { enough to continue, you know, trudging } \\
\text { through sexist [stuff] if I were a woman in } \\
\text { science.' }\end{array}$ \\
\hline & & $\begin{array}{l}\text { Positive: Recognition that } \\
\text { encourages participation } \\
\text { in physics. }\end{array}$ & $\begin{array}{l}\text { "... they fund out that I was a physicist and they } \\
\text { offered me the job as a physics teacher.' }\end{array}$ \\
\hline & & $\begin{array}{l}\text { Negative: Recognition that } \\
\text { discourages participation } \\
\text { in physics }\end{array}$ & $\begin{array}{l}\text { "'sorry I didn't acknowledge you, but I just } \\
\text { didn't have time to like prepare you, and I } \\
\text { didn't feel like...' He made It seem like he } \\
\text { didn't think I was dressed nicely enough" }\end{array}$ \\
\hline & & $\begin{array}{l}\text { Neither: But it is not clear } \\
\text { whether it encouraged or } \\
\text { discouraged their } \\
\text { participation. }\end{array}$ & $\begin{array}{l}\text { 'I feel like others see me as that as well. I've } \\
\text { been an active member of that community for, } \\
\text { I don't know I think five years maybe even } \\
\text { more. So yeah." }\end{array}$ \\
\hline
\end{tabular}

TABLE V. Details of our interest construct code definitions. This includes the definition of the main construct, as well as the definitions of each subcode and example from the interviews of Cara, Jeff, Cindy, or Owen.

\begin{tabular}{|c|c|c|c|}
\hline \multirow[t]{2}{*}{ Code } & \multicolumn{2}{|c|}{ Subcode } & \multirow{2}{*}{$\begin{array}{c}\text { Example } \\
\text { "[In] high school I was really } \\
\text { interested in STEM..." }\end{array}$} \\
\hline & $\begin{array}{l}\text { Content: Interest in physics } \\
\text { content }\end{array}$ & $\begin{array}{l}\text { Positive: Encouraging } \\
\text { participation in physics }\end{array}$ & \\
\hline \multirow{3}{*}{$\begin{array}{l}\text { Interest: Interest } \\
\text { in the physics } \\
\text { field }\end{array}$} & & $\begin{array}{l}\text { Negative: Discouraging } \\
\text { participation in physics }\end{array}$ & $\begin{array}{l}\text { "I didn't like science, I thought } \\
\text { it wasn't interesting." }\end{array}$ \\
\hline & $\begin{array}{l}\text { Non-Content: Interest } \\
\text { in physics for reasons other } \\
\text { than content }\end{array}$ & $\begin{array}{l}\text { Positive: Encouraging } \\
\text { participation in physics }\end{array}$ & $\begin{array}{l}\text { "So for me it's like yes I'm interested } \\
\text { in physics... I don't want to do } \\
\text { physics for the sake of physics..." }\end{array}$ \\
\hline & & $\begin{array}{l}\text { Negative: Discouraging } \\
\text { participation in physics }\end{array}$ & $\mathrm{N} / \mathrm{A}$ \\
\hline
\end{tabular}

\section{Competence and performance}

We combine the competence and performance constructs in concurrence with updated work [32] on the physics identity framework developed by Hazari et al. This construct is defined as one's beliefs in their ability to understand physics content and perform required physics tasks. We assign the same positive and negative subcodes to this construct as well, still defining them as encouraging and discouraging participation in physics. We use these subcodes to allow for the scenario where an interviewee's inability to understand content or perform the needed tasks in their physics careers can act as a motivator for a participant to work harder to continue their pursuit. An example of this from Cara's interview is in a story about her high school physics class. She did not do well in the class, and her teacher allowed her to do problems in the back of her physics book to make up the points lost: "In order to make it up [my teacher] told me to grab another physics book and work as many problems as I could in the back of the book, and he would give me points for every problem I worked." As she did them, she talks about gaining more excitement in the subject with every problem she was able to solve, and being able to boost her grade from doing this: "I just really got in the habit of liking trying to figure out these physics problems..." This example would be coded as positive competence and performance. Table VI outlines all the code definitions for competence and performance construct along with examples. 
TABLE VI. Details of our competence and performance construct code definitions. This includes the definition of the main construct, as well as the definitions of each subcode and example from the interviews of Cara, Jeff, Cindy, or Owen.

\begin{tabular}{|c|c|c|}
\hline Code & Subcode & Example \\
\hline \multirow{3}{*}{$\begin{array}{l}\text { Performance and competence: } \\
\text { Belief in ability to understand } \\
\text { and perform required tasks }\end{array}$} & $\begin{array}{l}\text { Positive: When an interviewee mentions good } \\
\text { performance and/or competence in physics } \\
\text { content }\end{array}$ & $\begin{array}{l}\text { "I just really got in the habit of liking trying to } \\
\text { figure out these physics problems, because if I } \\
\text { didn't get it right I didn't get points, and yet it } \\
\text { was material we hadn't covered at all, so that } \\
\text { really-I like, got a lot." }\end{array}$ \\
\hline & $\begin{array}{l}\text { Negative: When an interviewee mentions poor } \\
\text { performance and/or competence in physics } \\
\text { content }\end{array}$ & $\begin{array}{l}\text { "Well actually I... I did not do well in science in } \\
\text { middle school." }\end{array}$ \\
\hline & $\begin{array}{l}\text { Neither: When an interviewee mentions } \\
\text { performance and/or competence in physics } \\
\text { content but is not clear whether it is positive or } \\
\text { negative. }\end{array}$ & $\begin{array}{l}\text { "Where, again, it comes down to your } \\
\text { performance in class. They don't know you as a } \\
\text { researcher but they see you- because they aren't } \\
\text { working with you in your research group but in } \\
\text { their class, so do they see you a physicist?" }\end{array}$ \\
\hline
\end{tabular}

\section{CODING THE NARRATIVES}

We code our interviews using the operationalized Critical Physics Identity constructs outlined in the prior section by looking at the content and language of each narrative. In this section, we show excerpts of coded narratives from the interviews of Cara, Jeff, Cindy, and Owen in order to demonstrate how we use these constructs in our analysis process. The coded narratives in this section provide an example of how these constructs show up in the coding process. We choose sections of each narrative where there were multiple constructs in order to show how having these constructs in conversation with each other can shape the narratives. Because we plan to use this framework to specifically examine the different experiences of Black physicists, we are interested in examining how the operationalized codes show differences in experiences amongst the four participants. For this reason, we choose to show examples from these four physicists with very different backgrounds and identities. In Sect. VIIA, we will show how the coded narratives can highlight the broader social structures and systems at play, and how we plan to use this framework to do these types of analysis in the future.

\section{A. Cara}

Cara is a physicist who is a Black woman that has graduated with bachelor's and master's in physics, and a $\mathrm{Ph} . \mathrm{D}$. in education. She identifies as a physics education researcher but does not actively do research at her current job. Her pathway into the field began in high school, when she was given the opportunity to solve problems in the back of a textbook to make up her grade in her physics class. In her interview, she tells many stories about how she was discouraged by teachers and advisors from pursuing physics but was able to overcome this discouragement with her drive to face challenges. She talks frequently about important people and opportunities along her path that lead her to her current career, and how deciding not to continue in her physics program impacted the ways she identifies as a practicing physicist. In this excerpt from Cara's interview, shown in Fig. 2, she tells a story about her time in graduate school.

Cara's story starts off in response to the protocol question "what difficulties have you faced while pursuing the [physics] field?". The first sentence of her response talks about her experiences with imposter syndrome [57] while pursuing her Ph.D. in physics, a phenomenon that the

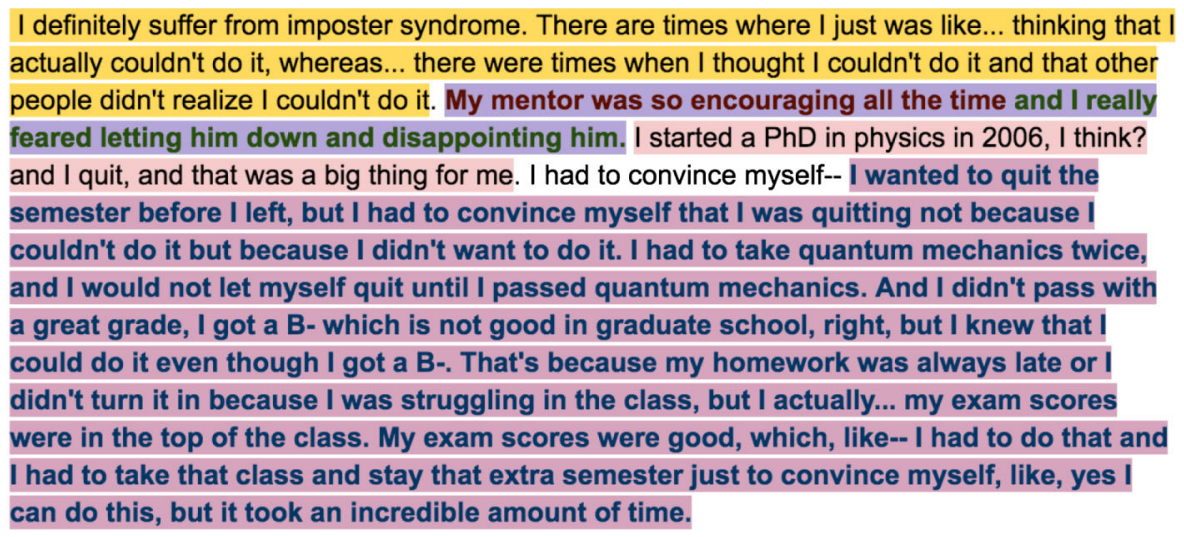

FIG. 2. An excerpt from Cara's coded interview using the Critical Physics Identity constructs. 
literature shows impacts women and people of color in academia: "I definitely suffer from imposter syndrome. There are times where I just was like... thinking that I actually couldn't do it, whereas... there were times when I thought I couldn't do it and that other people didn't realize I couldn't do it." We code the first sentence as an ideational resource talking about internal personal characteristics because of the language she uses as "suffering from" imposter syndrome. She then goes on to describe how this suffering means not only that she feared she could not do what she needed to do to get her degree, but also that others would discover that she was unable to do it. The following sentence talks about a positive relational resource through her advisor, who she described as always encouraging: "My mentor was so encouraging all the time and I really feared letting him down and disappointing him." Her response to that, however, was a negative internal recognition that manifested in her fear of disappointing him. Her narrative then moves on to talk about her decision to leave her physics Ph.D. program, and her push to prove to herself that should could be successful in the program before leaving. The physics Ph.D. program she decides to leave is coded as a negative material resource, because being in this program discouraged her participation in physics and lead her to leave for an education program. We code the sentences where she talks about her push to prove her abilities to herself as positive internal recognition. The details of this part of the story show that she was grappling with her competence and performance in her quantum mechanics class, and because she proved she was able to pass, so that construct is coded as positive.

\section{B. Jeff}

Jeff is a physicist who is a white man that has recently graduated with his bachelor's degree in physics. He is planning on beginning graduate school to get his Ph.D. in physics and has already been accepted to an institution. He has had many research experiences during his time in his undergraduate program and speaks a lot about a specific one during his interview. This particular research program impacted him greatly, because it had the most diverse population he had experienced in his career. He talks openly about being aware that he has privileges due to his identity as a white man in science. He describes his path into physics as something that was very easy, and somewhat predestined due to him having scientist parents. He discusses the tensions he holds around knowing that his friends and colleagues from marginalized populations go through harder times in the field. In the excerpt shown in Fig. 3, Jeff responds to the question "Do you think that your racial identity impacts the way you participate in physics?".

Interestingly, Jeff's response uses a story of others in the field to describe his own experiences. He first makes a statement about how the positive relational resource of having scientist parents is at the root of his identity as a scientist. He then mentions his identities as a white, heterosexual, and cis-gender male [58], in a statement that highlights how these personal characteristics allow him the ability not to have as many "interpersonal issues" as those with other identities. The story following this discusses his internal perceptions of the struggles that physicists who do not identify in the same way as him, being white and male, have to go through in order to pursue science fields. While doing this, he goes through a process of internal recognition of his positioning as a physicist, through the comparisons of his experiences to other relational resources provided by his relationships with his mother and friends.

\section{Owen}

Owen is a physicist who is a Black man in his first few years of a physics graduate program. He attended a Historically Black College for his undergraduate physics

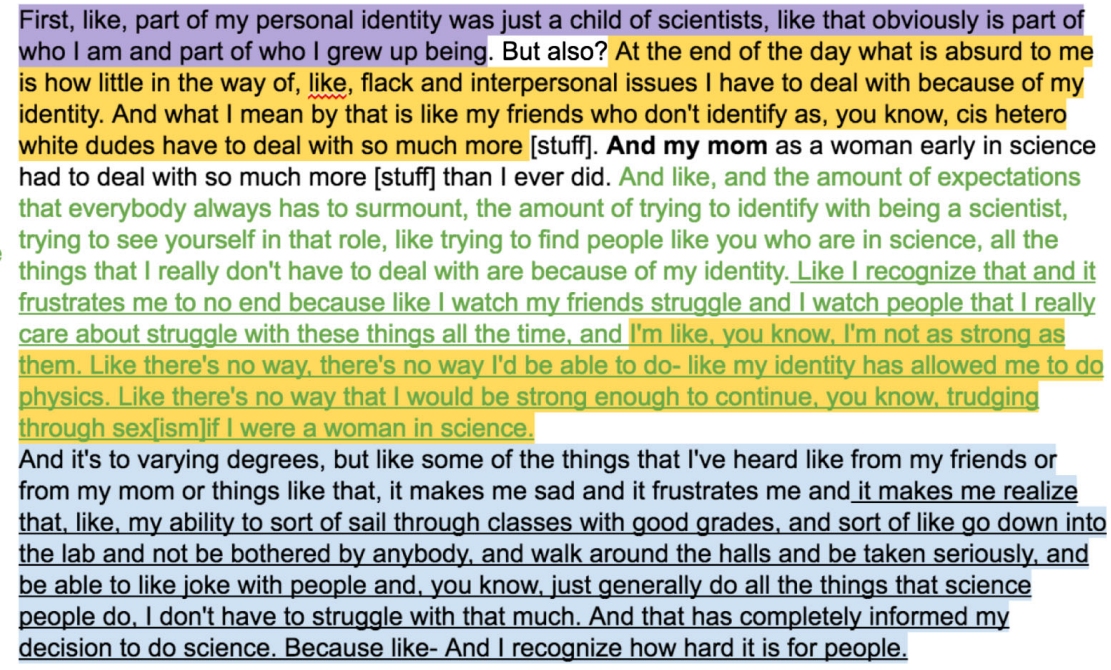

FIG. 3. An excerpt from Jeff's coded interview using the Critical Physics Identity constructs. 


\begin{abstract}
Oh, grad school. I think there was a transition in my life. So I graduated from college with my bachelor's and I actually applied to graduate school for engineering. I was looking at doing like aerospace engineering. I ultimately decided that this is- I still might be interested in it, but I didn't get accepted to any of the schools I applied to because I had not taken very specific courses that they wanted. So I ended up heading back home so I could like reapply the next semester

for graduate schools, and I ended up actually teaching though. They needed a teacher, a physics teacher, back in my home town, back in my high school. My physics teacher had retired and there was nobody that was teaching the class, and they found out that I was a physicist and they offered me the job as a physics teacher. So I figured l'd take this on for a year, in the time being I could also apply for graduate school and do something with engineering, you know, leave it. But I ended up actually really enjoying teaching, I loved teaching. I was coaching as well. So I kind of felt like I was having the best of both worlds, like I was learning, I was really learning physics now, like it wasn't just like this exploration, like oh, you know, there's such things as electrodynamics and thermodynamics and stuff. I was having to actually learn it because I had to teach it. I found so much joy in doing that, as well as working with students and like helping guide them along the way. I really enjoyed that.
\end{abstract}

Positive Material Resource Positive Competence/Performance Positive Non-Content Interest Positive Content Interes Negative Material Resource Positive External Recognition Positive Relational Resource

FIG. 4. An excerpt from Owen's coded interview using the Critical Physics Identity constructs.

degree, then transitioned into teaching afterwards. These experiences lead him to his interests in physics education research, but he discusses throughout his interview the struggles of being in his graduate program. In his story, he mentions many programs that he was able to participate in during undergrad that encouraged him to continue on his path; however, he highlights the time he spent teaching as an important experience for his physics identity. Figure 4 shows an excerpt of Owen's response to the question "How did you end up in physics?" He discusses the impacts that teaching at his old high school had on his trajectory into physics.

In response, Owen tells a story about how he was initially interested in pursuing engineering. After graduating from his undergraduate institution, he decided to apply for aerospace engineering programs: "I graduated from college with my bachelor's and I actually applied to graduate school for engineering. I was looking at doing like aerospace engineering." We code this part of the sentence as a positive material resource highlighting how his undergraduate degree gives him access to the credentials needed to apply to his graduate programs. However, he continues his story, discussing how he was unable to get into the programs he applied for: "I didn't get accepted to any of the schools I applied to because I had not taken very specific courses that they wanted." This part of the sentence we code as a negative material resource because his undergraduate experience lacked the requirements needed to admit him into an engineering graduate program. This lead him back to his hometown, where his old high school reached out to him for an opportunity to teach physics: "My physics teacher had retired and there was nobody that was teaching the class, and they found out that I was a physicist and they offered me the job as a physics teacher." We code the high school as a positive material resource, and the job offer as positive external recognition. His initial plan was to teach for a year while reapplying to another engineering program, but things changed when teaching became enjoyable to him: "I was really learning physics now, like it wasn't just like this exploration, like oh, you know, there's such things as electrodynamics and thermodynamics and stuff. I was having to actually learn it because I had to teach it. I found so much joy in doing that, as well as working with students and like helping guide them along the way. I really enjoyed that." He talks about how teaching actually made him learn physics more so than completing his degree, we code this as positive competence and performance. He then highlights how much he enjoyed the experience, and how working with kids positively impacted the experience as well. We code the beginning of this sentence as positive content interest because he states how learning physics through teaching was enjoyable. The second part of the sentence was coded as positive noncontent resource and positive relational resource.

\section{Cindy}

Cindy is a white woman in the first few years of a physics graduate program. She attended a Women's College for her undergraduate degree in physics and went straight into graduate school with a predominately white male department. Although she is in an electrical engineering Ph.D. program, she does research in a physics lab. She openly talks about the pressures of appearing and acting masculine while working in her lab, and how these pressures impact not only her day-to-day experiences, but how she is treated by others. One theme in her interview highlights the hard transition from her undergraduate program, where this concern was not an issue, to dealing with this in her current setting. In the interview, she tells a story about her advisor commenting on her clothing as a reason why he did not give her credit for her work to a collaborator from NASA. In the excerpt below, In the excerpt below, Cindy responds to the question "Do you identify as a physicist?". She discusses in detail how this idea of performing masculinity plays a role in her experience as a physicist. 


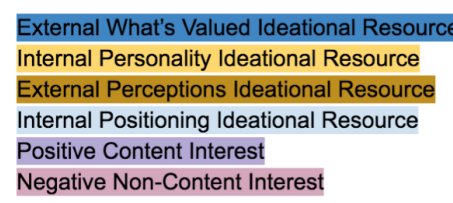

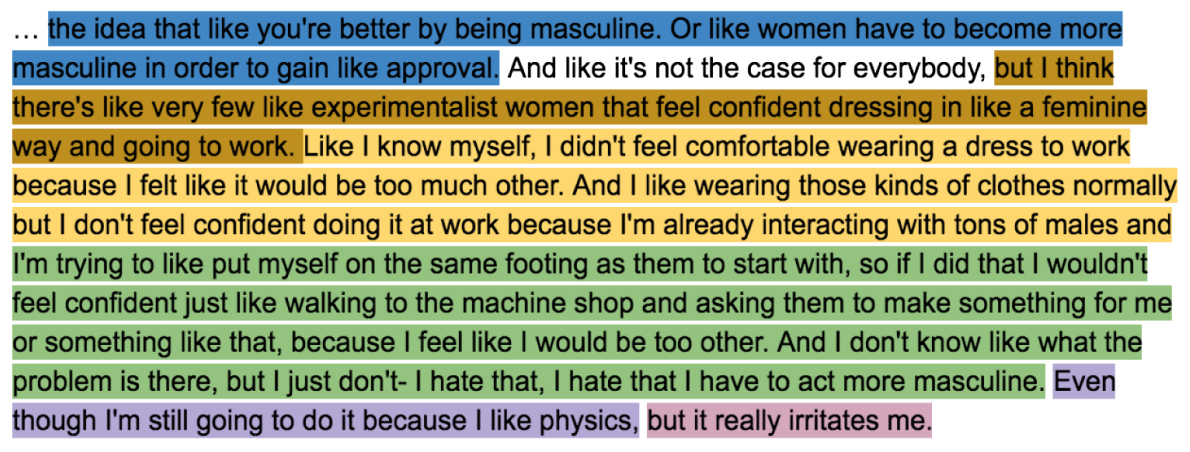

FIG. 5. An excerpt from Cindy's coded interview using the Critical Physics Identity constructs.
Cindy's response, shown in Fig. 5, began with comment about how she only partially identifies as a physicist and that she does not like the culture of physics.

The passage begins with a statement that Cindy makes after she is asked to elaborate on this: "...the idea that like you're better by being masculine. Or like women have to become more masculine in order to gain like approval." She specifically calls out an idea about the importance of masculinity in physics culture. We code this sentence as an ideational resource, but specifically as external what is valued and good in physics. She gets more specific in the following sentences about her opinions on this when she says: "I think there's like very few like experimentalist women that feel confident dressing in like a feminine way and going to work... I didn't feel comfortable wearing a dress to work because I felt like it would be too much other." She states that in general experimentalist women would not feel comfortable dressing feminine in the lab, which we code as an ideational resource, but specifically as external perceptions of physicists because she refers to feelings of other women who are experimental physicists. As she goes on she speaks about her own preferences, which we code as internal personal characteristics. She then shifts to talk about how this pressure to be masculine impacts her role in the lab: 'I'm trying to like put myself on the same footing as them to start with, so if I did that I wouldn't feel confident just like walking to the machine shop and asking them to make something for me... because I feel like I would be too other." We code this as internal positioning in physics because she indicates that she is already at an inferior level compared to her peers and dressing femininely will make things worse. The last few sentences shift out of the ideational resource subcodes when she states: "Even though I'm still going to do it because I like physics, but it really irritates me." We code these sentences as interest with the first part being positive content interest and second part being negative noncontent interest. Her love for physics content keeps her pushing through these tensions even though they are an irritation to her.

\section{SAMPLE APPROACHES TO ANALYSIS}

After coding the interviews, we identified some useful methods for recognizing the trends in the narratives that our constructs pull out. The first method looks at the differences in the numbers of codes in each interview. We examine this, which we name "frequency of codes," by evaluating the total number of instances that each construct was coded, as well as the percentages of each type of code. The second method examines connections in the ways that the constructs show up in the narratives. To identify patterns, we look for instances in the data where more than one of the coded constructs overlap in the narrative, as well as when constructs are frequently coded on after another within the narrative. In Sec. VIIIA, we show examples of these methods using data from the four interviews.

\section{A. Frequency of codes}

Examining the frequency of appearance of each of the constructs an interview can indicate which constructs were discussed most in the stories that were told. In Fig. 3, the full counts of codes in each participant's interview are shown to provide a preliminary analysis of Jeff, Cara, Cindy, and Owen's narratives. The first trend we notice in this graph is the high frequency of ideational resources for each person. Compared to the low numbers of competence and performance and interest codes, the ideational resources were brought up in the narratives more than twice as often for all subjects. We found the frequency of ideational resources in this sample interesting because we notice that many programmatic efforts focus on fostering interest in physics content. These numbers suggest that it is worth further understanding how internal and external ideational messages impact participation in physics. We also notice that generally the racialized resource constructs (ideational, relational, material) were overall coded more frequently than the physics identity constructs in this sample. This finding reaffirms the worth of foregrounding the racial identity framework in our analysis. Overall, from counting how many times each construct was coded, we are able to identify interesting trends from our four-person sample.

We see an example of one of these interesting differences when further examining the frequency of the material resource codes. In Fig. 6, we see that Owen has the most material resources coded. However, when looking further 


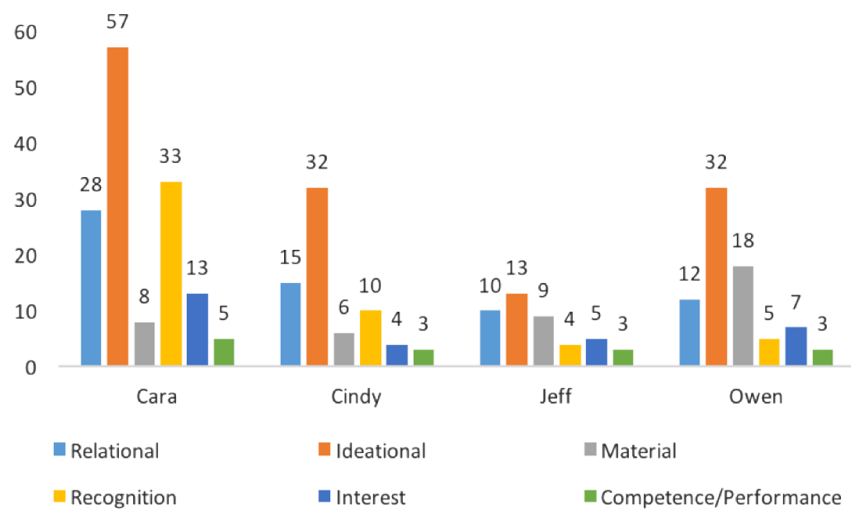

FIG. 6. The code counts for each construct in the Critical Physics Identity framework for each participant.

into the subcodes, we noticed a nuanced story. In Fig. 7, we show a graph of the percentage breakdowns for the material resources that were coded as positive, negative, and neither for each of the participants. From this graph, we can see that Jeff is the only one in the sample who did not discuss any negative material resources in his interview. Noting that he is the only white man in the sample, we consider this as an interesting point that will need to be examine further, with a larger data sample. Furthermore, we also noticed that Owen and Cara, the two Black physicists, have lower percentages of positive material resources, compared to Jeff and Cindy, as well as a higher percentage of material resources that are coded as neither. When we examine why this is, we see that these parts of the narrative include no specification of whether the material resource had a positive or negative impact on their participation in physics. We also noticed that these instances are usually connected to an ideational resource, which stresses the importance of triangulating among the quantitative coding, the narrative analysis, and the analysis to determine the overlap among codes.

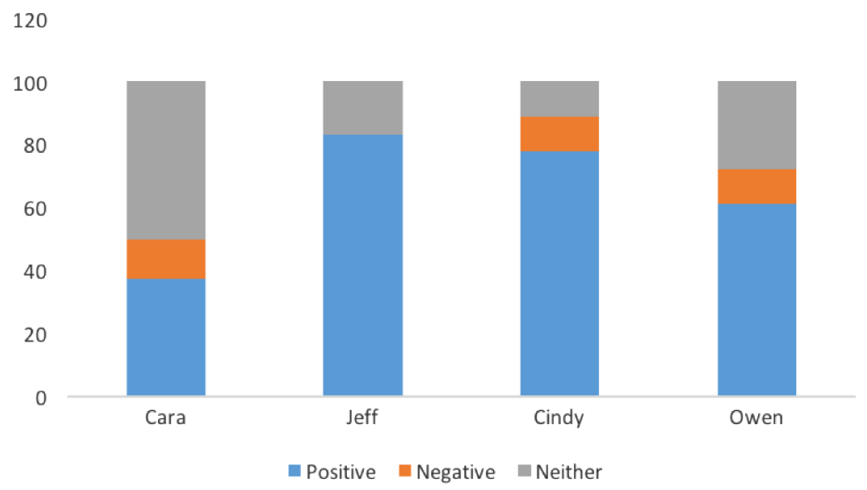

FIG. 7. The percentage of positive, negative, and neither material resource codes per participant. Each percentage is normalized to the total number of material resources that were coded in each participant's interview.
Although the counting of codes shows some interesting differences between the physicists in our sample, there are some limitations that arise from the normalization of these counts. These challenges to normalization include the different lengths of each interview, the different word counts, and the possibility of a person talking about one or two constructs for a long time, leaving less time for other constructs to be mentioned. Because we use a lens of narrative inquiry in our methodology we consider the time that each participant decides to spend talking about a construct as an indication of its importance. However, we acknowledge that these limitations can impact this as well. This is why we find it important to use a qualitative method of analyzing the trends in the data. In Sec. VIIIB, we outline two methods for doing this.

\section{B. Connecting constructs}

Beyond providing narratives and frequencies of the various constructs, we seek to understand how the operationalized constructs connect to each other. In order to connect the constructs, we identify two methods for measuring their connections: the overlap of multiple codes in data and repetitive consecutive codes. We see several instances where codes overlap and appear one after another frequently in the interviews of the four physicists. An example of overlapping codes can be seen in the data shown previously in Sec. VII. In these instances, the overlapping of codes brings out a nuanced part of a story. For example, we see this in the last sentence of Owen's excerpt where he says "working with students and like helping guide them along the way. I really enjoyed that." This was coded as both nonphysics content interest and positive relational resource in order to show how his interest in the relationships he was able to cultivate with students played a role in his interest in physics education research, and ultimately his decision to pursue a graduate degree in physics. Another example of this can be seen in Jeff's interview where he states "So I've sort of started thinking about who I'm going to live with next year at grad school, and my parents and all of my non-physics friends are like 'oh my god, it's going to be like The Big Bang Theory!' And I'm like okay, The Big Bang Theory is ... like a circus approximation of what physics life looks like." This segment was coded as a negative relational resource because Jeff goes on to explain his discomfort with his family and friend's assumptions of him. It was coded as perceptions of physicists' ideational resource as well because he describes how their perceptions of physicists comes from a popular TV show.

We also see instances where codes show up repeatedly one after another, even if they do not overlap. An example of this from Owen's excerpt is where he says "They needed a teacher, a physics teacher, back in my hometown, back in my high school. My physics teacher had retired and there was nobody that was teaching the class, and they found out 
that I was a physicist and they offered me the job as a physics teacher." The first sentence was coded as positive material resource, but the sentence following is coded as positive external recognition. A common connection we see is between relational resources and recognition. An example of when these two codes are coded one after the other can be seen in Cara's interview when she states: “...I had this professor. I was taking multivariable statistical analysis and this professor, long story short, was telling me why I wasn't doing well in the class although I hadn't turned in any assignments because no assignments were required, and he just assumed I wasn't doing well." This was coded as a negative relational resource because of the professor underestimating her, and as negative recognition because of the assumptions that the professor made. We also find that ideational resources and recognition have a specific way of connecting, where the positioning ideational code specifically connects with recognition often. An example of this happening is when Cindy says "I do kind of identify as a physicist, but like in other ways I strongly don't. So like I feel like there's like a culture of physics that I don't like, so." This was coded as both positioning ideational resource because she is explicitly talking about how she positions herself as a physicist while commenting on her dislike of the culture; it is also coded as internal recognition because her positioning acknowledges her identity as a physicist. We framed these two constructs in different ways, but they repeatedly pull out similar parts of the narrative. In future work we plan to explore these connections further in order to find common themes around why and when the codes that connect.

\section{CRITICAL PHYSICS IDENTITY MODEL CONNECTIONS}

With a goal to create a model to show how these constructs interact with each other, we pull initial indications of these construct connections from the three most common code connections in this four-person sample. The first is recognition and relational resource connections, often in discussions of a relationship with a person (mentor, friend, colleague) that gave them some form of recognition. The second is relational resource and ideational resource connections, where typically participants discuss an idea that people they know hold about them or about physicists broadly. The third is connections between recognition and ideational resources, which commonly occurs when participants are negotiating their positioning within the physics field. Figure 8 depicts a preliminary model for the connections we find between the Critical Physics Identity constructs when coded on this four person sample. The overall structure depicts the resources encompassing the physics identity constructs. Theoretically, we had initial thoughts of the resources being higher level constructs than the physics identity constructs; however, we see some slightly more nuanced connections emerge from our

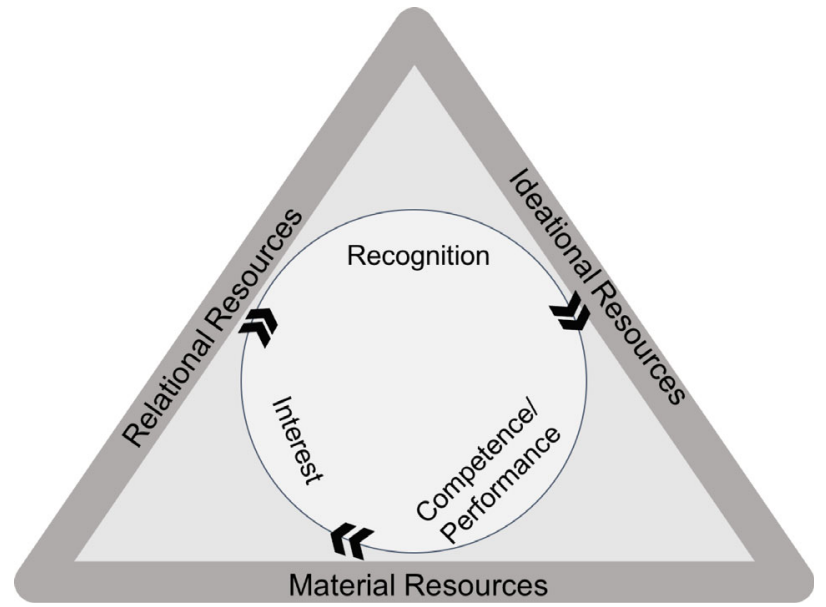

FIG. 8. Preliminary model for the Critical Physics Identity framework connections.

preliminary analysis presented here. We instead build this preliminary model with the resources surrounding the physics identity structures to represent how they can encompass the physics identity constructs, rather than situating them separately on a higher level. We see that the resources typically overlap with the physics identity constructs more so than each other in data, with the exception of relational resources and ideational resources. We place these two on the top of the triangle and closest to each other for this reason. We put the physics identity constructs inside the triangle of resources, with recognition situated between relational and ideational resources because of their recurring overlaps and repeated consecutive nature. We situate the interest and competence and performance closest to material resources for the same reason. The purpose of the arrows on the physics identity circle is to indicate the possibility for these patterned overlaps and connections between the resources and physics identity constructs to shift depending on the participant. It is important to note that we do not dismiss the possibility for all of the constructs to connect within a narrative in different ways than depicted in the model, rather we look to find common ways we see these connections occur in this specific sample.

From the analysis of the four participants in this work, we see that when the constructs are used together for coding, they regularly overlap within the narratives. The overlapping nature of the constructs has an interesting utility that brings out nuanced details in the experiences that physicists have while pursuing the field. In the framework, we use the racialized identity resources to call attention to the structures, ideas, and systems that impact the ways that physicists from marginalized backgrounds build an identity with the physics discipline. These resources impact the ways that the physics identity constructs show up in the stories of participants, and through our analysis we can identify themes and patterns within the 
narratives of practicing physicists that can give insights into what it takes for Black students to develop physics identities.

\section{A. Utility and value of the framework}

This is a critical framework, meaning it was created with the social justice intent to specifically examine physics culture through a critical lens. We consider this work a method to identify areas within the physics experience where we might be able to make changes in order to make the culture of the field more inclusive for all backgrounds. The framework allows us to simultaneously capture the narrative story of participants, while identifying structure and systemic features that impact individuals. By analyzing narratives using these overlapping constructs, one can reframe the hegemonic ideas around why certain people succeed in physics and others do not. In Cara's example from Sec. VII, the combination of personal struggles, her relationship with her mentor, and her internal battle for recognition, are all in negotiation in a story about a critical point in her career. The constructs overlap significantly in this story, in order to tell a broader story about how the accumulation of negative ideational resources and internal recognition lead to a different career choice. It is shown here how the constructs of the framework are coded based on the language used by the participant, as well as the events of the story, rather than how one might interpret them out of context.

A good example of how this framework can show some differences in experiences at the systemic level is the coding of the physics Ph.D. program as a negative material resource. It can be assumed that a physics Ph.D. program would be a material resource that encourages participation in physics, as that is its goal, but in Cara's experience being in the program did the opposite. Through the use of these constructs to examine her narrative, we can problematize the Ph.D. program as a system that did not encourage participation of a participant. We also see how even with a positive relational resource, and the competence and performance needed to pass her classes, Cara still decides to leave her physics program. Although she highlights her struggle with imposter syndrome, her drive to prove to herself that she is capable shows that there are other reasons why she made this decision. The framework brings out similar themes in Jeff's case study; we see how his awareness of his own ideational and relational resources from his parents and friends impacts his understanding of the norms within physics culture. The overlapping of the constructs elucidates how his ideas about his identity as a physicist along with his perception of how he functions as a physicist impact his ability to see how his experiences differentiate from the experiences of other physicists. Through the analysis of his entire narrative using the identity constructs, we can see the underlying concepts from this excerpt serve as a motivating factor for him to continue in physics and contribute to the change of the culture.

In addition, we can see differences across certain constructs in what we call the "weight" of the experiences that some of the participants described. We use the term weight to describe a way to compare the impacts of the experiences discussed by the interviewees to each other. An example of how these constructs can show these differences can be found in experiences coded as recognition and relational resources in Cara and Jeff's interviews. Cara describes an advisor who would not sign off on her physics course: "But that professor would not sign off for me to take calculus based physics because he said it would be too hard for me, and he put me in algebra based physics instead." This extreme example of a relationship being a barrier to physics is grouped in the same relational resource category as the experience Jeff has with his friends jokingly comparing him to the characters of Big Bang Theory: “...my parents and all of my non-physics friends are like 'oh my god, it's going to be like The Big Bang Theory! ...I don't feel like The Big Bang Theory-esque person, but other people do see me like that." It is clear that the discomfort that Jeff feels when being compared to characters on a television show has a different type of impact in comparison to Cara's experiences being obstructed from a course. We see this as an interesting finding that elucidates how these similarly coded structures in Cara and Jeff's narratives show important differences in their experiences.

We have an idea that there are common racialized experiences that Black physicists encounter while pursuing a physics degree or conducting work in the field. Future studies using this framework will focus on identifying these specific common experiences and what aspects of the systems within physics culture that impact these experiences. We believe that this framework and the related methodology can provide a more nuanced lens, specifically for the physics education research community, to take up identity in a new way that connects the systemic and structural factors to the individualized and collective experiences of people of color in the field. This framework can also provide useful information for bridging theory with practice by providing concrete implications for the design of programming aimed at increasing representation of Black physicists, as well as other physicists of color.

\section{B. Limitations}

Because the future goal for this work is to use this framework and analysis to categorize trends of experiences for Black physicists, it is important to account for the ways that this framework can and cannot be used to do so. The limitations of this work in part stem from the theoretical frameworks we draw upon. Nasir's racialized identity framework and Hazari et al.'s physics identity framework were both developed from studies focusing on people of color. Nasir's racialized identity framework study centered 
on Black high-school students and Hazari et al.'s physics identity framework pulled from Carlone and Johnson's study on women of color scientists. Because of these roots, we consider our framework to be most useful on populations of color, and most specifically Black folks. Although we used only interviews of Black and white physicists to operationalize the constructs, we are confident that the constructs can be used on other populations of color and have some validation of this utility from the second author who identifies as a Latina physicist. We outline three important limitations of this work: one of the sample used, and two limitations of the utility of our analysis.

Limitations of the process used to operationalize the constructs can be seen in the small sample of data used. We chose physicists from largely different backgrounds to demonstrate the utility of this framework in capturing a wide range of experiences, but not yet to make claims about themes. In doing this, we also picked physicists at different places in their careers. For example, our sample includes a white man, Jeff, at the beginning of his career, and a Black woman, Cara, further into her career. This selection we choose because of the intent of this framework to highlight the structures, systems, and ideas about which the participants talk. The differences in the place in career of Cara and Jeff can impact the number of constructs that they speak about, which can impact the framework's utility to do large scale comparisons across this dimension. In order to make such comparisons, there is still work to be done around defining normalization measures for the code counts that address the time lengths and word counts of the interviews. It is important to note that we intentionally include physicists at different points in their careers in our sample in order to see themes that emerge despite the stage of one's career.

We see an important limitation of the framework in capturing how participants express the degree of impact that each construct had on their experience and pathway, An example of this is can be seen when Cara responds to the question "how has physics impacted your [social] life?": “...like I went to a conference for women of color in STEM and there were three of us who had physics backgrounds, and we just like-we became the best of friends like immediately, you know, and stayed in touch and continue to support each other in all kinds of stuff, even when I miss my physics friend, okay, so like even in health we're like supporting each other because there's just some... there's so many things that you share being a part of that minority group of Black women in physics." She talks about her experience finding friends at a conference for women of color in STEM fields and describes the importance of this group of friends and how they support each other. We label this effusive sentiment one time in the transcription as a relational resource. Thus, this section is coded in the same category as other relational resources that Cara emphasizes less. For example, another statement that was coded this way was how she liked her undergraduate physics professors: "the physics professors were awesome." This statement, although obviously positive, is less clear how much more important this was in comparison to her support group of minority women scientists that she discussed in the first excerpt.

\section{CONCLUSION}

In this paper, we have developed a tool to critically examine physics identity with special attention to the impacts of structural and systemic racism. We then demonstrated how we applied it to data and provided examples of the types of findings it can produce. Future work will expand on outcomes finding from application of this tool and approaches to broader samples. The experiences that Black physicists have while pursuing physics is important to understand in order to increase the representation of Black physicists. While we focus this work on the experience of Black physicists, we know that there are many marginalized communities in the field who face similar issues when encountering physics culture. Understanding how this impacts how we do physics and who gets to do physics is crucial for the growth of the field. There is a growing need for more critical work in physics education research, both theoretical and empirical, in order to push the field of physics forward into a more inclusive and equitable future. Here, we have taken steps in this direction. We invite others to use this framework to more critically examine the ways that marginalized students identify with the discipline. A long-term goal of this work is to connect our research findings to concrete changes in institutions and systems through the creation of informal science educational programs that take up pedagogies and content from the arts in order to create a more inclusive physics education space. With this goal in mind, we find value in considering the many intersecting identities that one can have and how they can create nuanced experiences amongst physicists who share marginalized identities. In our next study, we will apply this framework and analysis to a larger sample of Black students in order to determine implications for programmatic efforts. We will categorize broad themes and patterns that highlight the experiences of systemic oppression that Black physicists face while pursuing studies and careers in the field of physics. Utilizing our Critical Physics Identity framework, we can begin to tease apart the experiences of physicists from different backgrounds, allowing us to focus in on the tensions being negotiated along their paths.

\section{ACKNOWLEDGMENTS}

The authors would like to acknowledge the NSF AISL \#1423496 and Graduate Research Fellowship grants that funded this work. We would also like to acknowledge Tamia Williams, who served as an undergraduate researcher on this project. We also thank the reviewers who provided useful feedback that led to this published draft. 
[1] R. Czujko, R. Ivie, and J. H. Stith, Untapped talent: The African American presence in Physics and the Geosciences, AIP Report. Number R-444 (Statistical Research Center of the American Institute of Physics, College Park, $\mathrm{MD}, 2008)$.

[2] L. Merner, African American participation among Bachelors in the Physical Sciences and Engineering, AIP Focus On (AIP, College Park, MD, 2015).

[3] Z. Hazari, G. Sonnert, P. Sadler, and M. Shanahan, Connecting high school physics experiences, outcome expectations, physics identity, and physics career choice: A gender study, J. Res. Sci. Teach. 47, 978 (2010).

[4] N. Nasir, Racialized Identities: Race and Achievement among African American Youth (Stanford University Press, Stanford, CA, 2011).

[5] National Science Foundation, Women, Minorities, and Persons with Disabilities in Science, and Engineering: 2007 (National Science Foundation, Division of Science Resource Statistics, Arlington, VA, 2007).

[6] J. Williams, K. W. Phillips, and E. V. Hall, Double Jeopardy?: Gender Bias Against Women of Color in Science (Hastings College of the Law, Center for WorkLife Law, San Francisco, CA, 2014).

[7] Racial and Ethnic Minority Student Success in STEM Education: ASHE Higher Education Report, edited by S. D. Museus, R. T. Palmer, R. J. Davis, and D. Maramba (John Wiley \& Sons, New York, 2011), Vol. 36, No. 6.

[8] S. Hurtado, C. B. Newman, M. C. Tran, and M. J. Chang, Improving the rate of success for underrepresented racial minorities in STEM fields: Insights from a national project, New Dir. Inst. Res. 2010, 5 (2010).

[9] S. M. Malcom, P. Q. Hall, and J. W. Brown, The Double Bind: The Price of Being a Minority Woman in Science (American Association for the Advancement of Science Washington, DC, 1976).

[10] A. Calabrese Barton, H. Kang, E. Tan, T. B. O’Neill, J. Bautista-Guerra, and C. Brecklin, Crafting a future in science: Tracing middle school girls' identity work over time and space, Am. Educ. Res. J. 50, 37 (2013).

[11] Z. Zacharia and A.C. Barton, Urban middle-school students' attitudes toward a defined science, Sci. Educ. 88, 197 (2004).

[12] P. H. Miller, S. V. Rosser, J. P. Benigno, and M. L. Zieseniss, A desire to help others: Goals of high-achieving female science undergraduates, Women's Studies Quarterly 28, 128 (2000).

[13] L. Espinosa, Pipelines and pathways: Women of color in undergraduate STEM majors and the college experiences that contribute to persistence, Harv. Educ. Rev. 81, 209 (2011).

[14] M. Ong, C. Wright, L. Espinosa, and G. Orfield, Inside the double bind: A synthesis of empirical research on undergraduate and graduate women of color in science, technology, engineering, and mathematics, Harv. Educ. Rev. 81, 172 (2011).

[15] S. J. Robinson, Spoketokenism: Black women talking back about graduate school experiences, Race Ethnicity Educ. 16, 155 (2013).

[16] B. A. Burt, A. Knight, and J. Roberson, Racializing experiences of foreign-born and ethnically diverse Black male engineering graduate students: Implications for student affairs practice, policy, and research J. Int. Students 7 (2017).

[17] D. Bilimoria and K. K. Buch, The search is on: Engendering faculty diversity through more effective search and recruitment, Change: The Magazine of Higher Learning 42, 27 (2010).

[18] R. E. Zambrana, R. Ray, M. M. Espino, C. Castro, B. Douthirt Cohen, and J. Eliason, "Don't leave us behind": The importance of mentoring for underrepresented minority faculty, Am. Educ. Res. J. 52, 40 (2015).

[19] J. A. Whittaker and B. L. Montgomery, Cultivating diversity and competency in STEM: Challenges and remedies for removing virtual barriers to constructing diverse higher education communities of success, J. Undergraduate Neurosci. Educ. 11, A44 (2012).

[20] K. L. Zeiser, R. J. Kirshstein, and C. Tanenbaum, The Price of a Science PhD: Variations in Student Debt Levels Across (2013), https://www.air.org/sites/default/files/ downloads/report/AIRPriceofPhDMay13_0.pdf.

[21] National Academies of Sciences, Barriers, and Opportunities for 2-year, and 4-year STEM Degrees: Systemic Change to Support Students' Diverse Pathways (National Academies Press, Engineering, and Medicine, Washington, DC, 2016).

[22] E. O. McGee, Devalued Black and Latino racial identities: A by-product of STEM college culture?, Am. Educ. Res. J. 53, 1626 (2016).

[23] E. O. McGee and L. Bentley, The troubled success of Black women in STEM, Cognit. Instr. 35, 265 (2017).

[24] M. Ong, J. M. Smith, and L. T. Ko, Counterspaces for women of color in STEM higher education: Marginal and central spaces for persistence and success, J. Res. Sci. Teach. (2017).

[25] R. Kachchaf, L. Ko, A. Hodari, and M. Ong, Career-life balance for women of color: Experiences in science and engineering academia, J. Diversity Higher Educ. 8, 175 (2015).

[26] M. A. Beasley and M. J. Fischer, Why they leave: The impact of stereotype threat on the attrition of women and minorities from science, math and engineering majors, Social Psychol. Educ. 15, 427 (2012).

[27] D. R. Johnson, Campus racial climate perceptions and overall sense of belonging among racially diverse women in STEM majors, J. Coll. Student Dev. 53, 336 (2012).

[28] L. Rosenthal, B. London, S. R. Levy, and M. Lobel, The roles of perceived identity compatibility and social support for women in a single-sex STEM Program at a coeducational university, Sex Roles 65, 725 (2011).

[29] T. L. Strayhorn, Sense of belonging and african-american student success in STEM: Comparative insights between men and women, Beyond Stock Stories and Folktales: African Americans' Paths to STEM Fields (Emerald Group Publishing Limited UK, 2011), Chap. 10, pp. 213-226.

[30] G. Trujillo and K. D. Tanner, Considering the role of affect in learning: Monitoring students' self-efficacy, sense of belonging, and science identity, Cell Biol. Educ. 13, 6 (2014).

[31] V. Sawtelle, E. Brewe, and L. H. Kramer, Exploring the relationship between self-efficacy and retention in introductory physics, J. Res. Sci. Teach. 49, 1096 (2012). 
[32] M. Soldner, H. Rowan-Kenyon, K. K. Inkelas, J. Garvey, and C. Robbins, Supporting students' intentions to persist in STEM disciplines: The role of living-learning programs among other social-cognitive factors, J. Higher Educ. 83, 311 (2012).

[33] Agency of women of color in STEM: Individual and institutional strategies for persistence and success, Pathways, Potholes, and the Persistence of Women in Science: Reconsidering the Pipeline, edited by M. Ong and E. H. Branch (Lexington Books Lanham, MD, 2016), pp. 183-195.

[34] L. T. Ko, R. R. Kachchaf, A. K. Hodari, and M. Ong, Agency of women of color in physics and astronomy: Strategies for persistence and success, J. Women Minorities Sci. Eng. 20, 171 (2014).

[35] L. L. Espinosa, The academic self-concept of African American and Latina (o) men and women in STEM majors, J. Women Minorities Sci. Eng. 14, 177 (2008).

[36] F. A. Herrera, S. Hurtado, G. A. Garcia, and J. Gasiewski, A model for redefining STEM identity for talented STEM graduate students, in Proceedings of the American Educational Research Association Annual Conference (AERA, Washington, DC, 2012).

[37] A. Johnson, J. Brown, H. Carlone, and A. K. Cuevas, Authoring identity amidst the treacherous terrain of science: A multiracial feminist examination of the journeys of three women of color in science, J. Res. Sci. Teach. 48, 339 (2011).

[38] H. B. Carlone, C. M. Scott, and C. Lowder, Becoming (less) scientific: A longitudinal study of students' identity work from elementary to middle school science, J. Res. Sci. Teach. 51, 836 (2014).

[39] H. Carlone and A. Johnson, Understanding the science experiences of successful women of color: Science identity as an analytic lens, J. Res. Sci. Teach. 44, 1187 (2007).

[40] Z. Hazari, P. M. Sadler, and G. Sonnert, The science identity of college students: Exploring the intersection of gender, race, and ethnicity, J. Coll. Sci. Teach. 42, 82 (2013).

[41] K. Rosa and F. M. Mensah, Educational pathways of Black women physicists: Stories of experiencing and overcoming obstacles in life, Phys. Rev. Phys. Educ. Res. 12, 020113 (2016).

[42] M. Ong, Body projects of young women of color in physics: Intersections of gender, race, and science, Social problems 52, 593 (2005).

[43] L. T. Ko, R. R. Kachchaf, M. Ong, and A. K. Hodari, Narratives of the double bind: Intersectionality in Life Stories of Women of Color in Physics, AIP Conf. Proc. 1513, 222 (2013).
[44] M. Esteban-Guitart and L. C. Moll, Funds of Identity: A new concept based on the Funds of Knowledge approach, Culture Psychol. 20, 31 (2014).

[45] R. M. Lock, Z. Hazari, and G. Potvin, Physics career intentions: The effect of physics identity, math identity, and gender, AIP Conf. Proc. 1513, 262 (2013).

[46] E. W. Close, H. G. Close, and D. Donnelly, Understanding the learning assistant experience with physics identity, AIP Conf. Proc. 1513, 106 (2013).

[47] P. W. Irving and E. C. Sayre, Identity statuses in upperdivision physics students, arXiv:1505.07801.

[48] E. O. McGee and D. Stovall, Reimagining critical race theory in education: Mental health, healing, and the pathway to liberatory praxisEduc. Theory 65, 491 (2015).

[49] P. H. Collins, Black Feminist Thought: Consciousness Knowledge, and the Politics of Empowerment (Unwin Hyman, Boston, 1990).

[50] b. Hooks, Feminism is for Everybody: Passionate Politics (South End Press Cambridge, MA, 2000).

[51] S. Hyater-Adams, K. Hinko, and N. Finkelstein, Pathways to STEM: Understanding Identity of Adult Physicists through Narrative Analysis, in Proceedings of the Physics Education Research Conference 2015 College Park, MD, edited by A. D. Churukian, D. L. Jones, and L. Ding (AIP, New York, 2015), pp. 151-154.

[52] S. Hyater-Adams, C. Fracchiolla, K. Hinko, and N. Finkelstein, Understanding connections between physics and racial identities through recognition and relational resources, in Proceedings of the Physics Education Research Conference 2016 Sacramento, CA, edited by D. L. Jones, L. Ding, and A. Traxler (AIP, New York, 2016), pp. 164-167.

[53] F. M. Connelly and D. J. Clandinin, Stories of experience and narrative inquiry, Educ. Researcher 19, 2 (1990).

[54] See Supplemental Material at http://link.aps.org/ supplemental/10.1103/PhysRevPhysEducRes.14.010132 for the full interview protocol used in this study.

[55] K. A. Hinko, P. Madigan, E. Miller, and N. D. Finkelstein, Characterizing pedagogical practices of university physics students in informal learning environments, Phys. Rev. Phys. Educ. Res. 12, 010111 (2016).

[56] Da'Shawn Mosley, Hidden racism, Sojourners 23 Feb. 2017 (accessed 18 May 2017).

[57] A. Parkman, The imposter phenomenon in higher education: Incidence and impact, J. Higher Educ. Theory Pract. 16, 51 (2016).

[58] R. Edwards, Trans-poetics, Transgender Studies Quarterly 1, 252 (2014). 